aggravated, the urine slightly bloody, and the debility ex-essive.

Jan. 21st. Improvement began, and continued until the 23 rd, when he was so much better that he was able to eat com. fortably, and once again sat up while his bed was being made. Care being taken to prevent undue muscular exertion, he escaped any more myalgic pains until the 25th. During that day he had been "roaring" with laughter and fun, and had been sitting up in bed for the greatest part of the afternoon. At night, after a short sleep, he was awaked crying with severe pain in the jliac and pubic regions, which lasted for about six hours. On the $26 \mathrm{th}$, he was too sore to move or to talk. On the 27 th, he was much better, and lively enough to play; but, fearing to sit up, he only raised himself on one elbow, in the position assumed by the Greeks at their symposia. This position threw much strain upon the sterno-mastoid of the left side; and the result was, that a very intense pain in that muscle came on at night, with much swelling and tenderness, and difficuity of swallowing. After this, he became very fearfu of moving, and lay quietly until February 1st, when he was again full of fun, and laughed and talked with more than usual vivacity. 'The same result followed, and the pain was referred to the trarus, the sterno-hyoid and thyroid, the omohyoid, and the platysma. The next day, he was too sore to move. During the whole of the complaint, the debility was excessive, and hematuria twice occurred, passing away on each occasion in twenty-four hours, without special treatment. He was able to leave home for change of air on February $10 \mathrm{th}$ but remained subject to myalgia for many weeks. On one occasion, the 19th, $20 \mathrm{ih}$, and 21 st of January, I felt no doub that there was genuine inflammation, which had commenced in the sterno-mastoid, and had spread to the parts around, in cluding the pharyngeal muscles and the faucial mucous membrane.

Dr. Sandwith of Beverley has told me of a case in which this state of things eventuated in permanent wryneck, for the cure of which he subsequently operated. On making a section of the muscle, he found it converted into a substance of almost cartilaginous appearance of hardness.

CASE vir. The next case is one where, after scarlatina, the myalgia was so general as to lead to the fear of acute rheumatic fever.

J. M. J., aged 10, a tall overgrown girl, of strumous habit, had a very mild attack of scarlet fever, but which was complicated by two attacks of hæmaturia, much vomiting, and by a serious epi leptic seizure. 'The fever began January 22nd; and by February 26 th she was sufficiently recovered to go to Southpor for change of air. The journey involved a walk down stairs and to a car, a drive to the railway (one mile), a walk to the train (a hundred yards), a ride of an hour, a walk to a car (twenty yards ), a drive of five hundred yards, and a walk into the house (twenty yards). On her arrival, she seemed to be in excellent health and spirits, and not to be at all fatigued; but, on the next day, she complained of intense pain and tenderness all over the body, and especially about the knee and ankle joints. This obliged her to keep to bed for two days, after which she slowly began to recover; but a whole week elapsed ere she could place one heel in advance of the other toe while walking, and three months elapsed ere she could sit up for more than two hours without having inframammary pain, on the one side or the other, according as she had been sitting. The last attack of hæmaturia lasted for four months ere it disappeared. No special treatment was adopted, nor did there appear to be any mischief resulting. She has since that period continued in perfectly good health.

Remarks. These cases are sufficient to show-1. That ex cessive use of a muscle may produce an inflammatory condi tion; 2. That this condition may subside without suppuration or organic change; 3. That "resolution" is favoured by absolute rest; 4 . That this condition is induced by what appears to be very slight exertion; 5. That slight exertion becomes exces. sive when beyond the patient's strength; 6 . That the existence of myalgia, from apparently trivial causes, implies the presence of debility or cachexia; 7 . That this cachexy may be constitutional or accidental-e.g., from anorexia, from prolonged use of aperients, or from scarlatina; 8. That the diagnosis of a case is not completed when "myalgia" is made out, but that it is necessary still farther to investigate the circumstances pro. ducing it. They suggest the idea-a. That the severe pains so common in scurvy, and the brawny hardness so constantly met with in the hams, calves, and thighs, in that complaint, are due to myositis, from ovesexertion, in individuals weakened by scorbutic cachexia; $b$. That the hardness of the abdominal walls, so common in cancerous affections and in inflammation of the liver, may be due to myositis, the result of nverexertion in a cachectic subject, or from the spread of inflammation from the liver to the recti and obliqui; $c$. That the few cases in which myalgic pains are relieved by local bleeding are those in which overexertion has produced a quasi-inflammatory condition in the affected muscle; $d$. That the condition of the abdominal walls referred to must always complicate the diagnosis of abdominal tumours; $e$. That, in all cases of suspected abdominal disease, the examination must be made with the greatest possible gentleness, so as not to provoke the irritable muscles to contract.

In conclusion, I would remark, that any one who wishes to ascertain for himself the power of the muscular system under varying circumstances may do so by using Hutchinson's spirometer. He will find in his own person that he can blow it up high or low, according to his condition at the time. So sensitive is this test, that the influence of a day's fatigue, diarrhœa, influenza, and the like, are all marked by a diminution of the amount expired, varying from five to twenty cubic inches. In fact, the spirometer is not simply an index of the state of the lungs, but is an index of the inflating power. I have often noted that those of consumptive tendency, though of sound lungs, are the most subject to myalgia; it is in them also that we meet with the greatest deficiency of respiratory power, as shown by the spirometer.

\section{TURNING AS A SUBSTITUTE FOR THE FORCEPS IN CASES OF NARROW PELVIS.}

\section{By Robert Jones, Esq., Strefford.}

IN a series of papers published some years ago in this JoUnNaL, Dr. Simpson advocated the operation of turning in labours connected with narrow pelves, in preference to the use of the long forcens or craniotomy, provided it be had recourse to early, as being attended with less danger to the mother, and as affording a greater chance of saving the life of the child. He states that morbid contraction of the brim is, whatever mode of delivery be adopted, liable to cause rupture of the uterus, especially when the labour has been allowed to be protracted, and the compressed tissues of the cervix have consequently been rendered friable; and that, owing to the elasticity of the cranial bones, great force might be used in extracting the head, without endangering the child's life, etc.

The following case is related as corroborative of these views. A few years ago, early in May, Mrs. Cook requested me to attend her in her forthcoming confinement. She is a little spare Irishwoman, aged 38 , the wife of a coachman. She had then nearly completed the eighth month of her eighth pregnancy. She informed me that her first four labours were tedious and painful; the children were small, but born alive, and were still living; that, in her two next confinements, she was attended by two different medical men, both living at Leintwardine; that in each the labour was painful and very protracted, and craniotomy was had recourse to in each. In her seventh confinement, which happened eighteen months ago, she was attended by a gentleman practising in Ludlow this time the labour lasted thirty hours; it was left to nature, and the child was born dead.

I took this history as sufficient evidence of the existence of a morbidly contracted pelvis, and at once suggested the induction of premature labour. To this my patient stoutly objected. 'There was, therefore, nothing for it but to wait the natural time. Accordingly, early in the morning of the following 2 lst of June, I was sent for. I found she had been in labour all night, and for the four last hours the pains had been very powerful. The vagina was well lubricated, the sacrum very hollow, and the promontory greatly projecting forwards. The os uteri was well dilated, the membranes entire, and the child's head just entering the brim. With a trifling degree of force, I pushed back the head, carried my hand into the uterus, and brought down the feet without the least difficulty. Not so, however, with the head; for this required all or nearly all the strength I could use and keep up for some minutes. The head at length passed. The child was apparently dead; but the funis beat feebly, and at long intervals. Cold water being gently dashed on the face repeatedly, the child gasped, cried, and ultimately breathed well, and, I believe, is still living. The mother made a good recovery. 